\title{
Utilizing a Process Management Approach to Standardise the Application of Value Stream Mapping
}

\author{
Peter Kuhlang \\ Thomas Edtmayr \\ Alexander Sunk \\ Christian Morawetz \\ Wilfried Sihn \\ Vienna University of Technology and Fraunhofer Austria Research GmbH, \\ Vienna, Austria
}

\begin{abstract}
The systematic improvement of processes is practically realised in the industry and economy by operating a Process Management (PcM) System. Many authors also recommend a systematic repetition of Value Stream Mapping (VSM); but the global experiences in applying VSM do more or less indicate a single or punctual application of VSM to improve processes or value streams. The findings discussed in this paper describe the systematic embedding of Value Stream Mapping into the life cycle of a Process Management System using the principles of "innovation and continuous improvement". Thus the Process Management System enables a systematic, regularly repeating application of VSM by extending its 4-Step-procedure (method, approach). One suitable way to standardise the application of VSM is specified in this paper on a theoretical base to make this approach international applicable.
\end{abstract}

Keywords: Value stream mapping, Process management, Process life cycle.

\section{Introduction}

Practical application and current research activities have shown similarities between the approach of Process Management (PcM) and the approach of Value Stream Mapping (VSM) in many aspects. It is obvious, that a combination of these two methods provides mutual benefits and synergies and offers the opportunity for improved new procedures to apply these methods. VSM is an internationally used, successful method usually applied in single projects with high innovative impacts and should be developed towards a more continuous application by being embedded into a systematic Process Management approach. Process Management presents a systematic and cultivating approach, which does not exist in the VSM projects accomplished based on Rothers' and Shooks' (Rother and Shook, 2006) approach. So far only a repeated application of the 4 step method is recommended, but it is not described explicitly (Rother and Shook, 2006; Wiegand and Franck, 2006; Erlach, 2007; Klevers, 2007; Duggan, 2007). These days a systematic Process Management System has been introduced and approved in countless enterprises and The application of VSM based on Rother and 
Shook has become some kind of "quasi-standard" in analyzing processes all over the world. Chart 1 provides the opportunity to identify synergies of the joint application of VSM and PcM based on their fundamental principles, perspectives and constraints.

This situation respectively these opportunities motivated us to raise thoughts and questions considering a join application of these two methods and we documented our theoretically and conceptual considerations in this paper. Our objective is to introduce a procedure to standardize the application of VSM based on the two fundamental organization development principles "innovation" and "continuous improvement" both provided by the Process Management approach applied here.

\section{Research Methodology}

The following remarks show from a theoretical point of view how the embedding of VSM into a systematic Process Management System can be realised thus enabling VSM to become a part of phases of the Process Life Cycle at the same time. Own practical experiences in VSM projects indicate a clear need to standardise the firm integration of VSM in improvement routines. Reviewing the existing literature considering case studies describing Lean Manufacturing case studies and VSM in combination with simulation carried out by Abdulmalek and Rajgopal (2007) and Gurumurthy and Kodali (2011) as well as the literature review described by and Vinodh et al. (2010) show clear evidence that a standardization of the application of VSM is not yet discussed in the scientific community. The current discourse in practical application and the scientific German-speaking world may be used as a nucleus to initiate further development and considerations on an international base. The ideas, developed on hypothetical and conceptual considerations, describe the way to attain

Chart 1. Fundamental principles, perspectives and constraints.

\begin{tabular}{|c|c|}
\hline Value stream mapping & Process management \\
\hline \multicolumn{2}{|c|}{ Fundamental principles and perspectives } \\
\hline $\begin{array}{l}\text { Prevent waste, reduce lead time } \\
\text { (Lean Thinking) }\end{array}$ & $\begin{array}{l}\text { Grooming and structuring approach covering } \\
\text { the whole organisation }\end{array}$ \\
\hline Keen on efficiency perspectives & Keen on effectiveness perspectives \\
\hline $\begin{array}{l}\text { Figures, facts and data oriented } \\
\text { point in time perspective }\end{array}$ & $\begin{array}{l}\text { Strategy considerations and } \\
\text { period of time perspective }\end{array}$ \\
\hline $\begin{array}{l}\text { Clear principles and guidelines to define and } \\
\text { reach a target status }\end{array}$ & $\begin{array}{l}\text { Innovation und continuous improvement } \\
\text { adopted as principles in the Process Life Cycle }\end{array}$ \\
\hline $\begin{array}{l}\text { Process control information } \\
\text { are taken into consideration }\end{array}$ & $\begin{array}{l}\text { Several different views on the organisation } \\
\text { (customer, information, risc, interfaces, IT) } \\
\text { are taken into consideration }\end{array}$ \\
\hline $\begin{array}{l}\text { Paper and pencil visualisation tool } \\
\text { (easy and quick application) }\end{array}$ & $\begin{array}{c}\text { Focuses on establishing an process-oriented } \\
\text { Management System }\end{array}$ \\
\hline \multicolumn{2}{|c|}{ Constraints } \\
\hline $\begin{array}{l}\text { Highly networked and } \\
\text { derived processes }\end{array}$ & $\begin{array}{l}\text { Effects of improvement become visible only } \\
\text { in mid-term considerations }\end{array}$ \\
\hline $\begin{array}{l}\text { Processes with } \\
\text { non-materialised products }\end{array}$ & $\begin{array}{l}\text { Figures, fact and data are often not specific } \\
\text { enough; Benefits can often not be quantified }\end{array}$ \\
\hline
\end{tabular}


systematic improvement of processes lasting, recurrently and on a regular basis. The basic hypothesis we formulated is that Value Stream Mapping is methodically expanded by the holistic aspects of Process Management Systems. The orientation of Value Stream Design to increase efficiency is broadened by the aspects of increasing effectiveness and continuous improvement.

\section{Fundamental Principles to Systematise VSM}

All natural systems and therefore processes too, are constantly changing. A process, that has once reached a certain performance level, is likely to loose that level in a natural way. Standards - such as aims and guidelines - stabilise the process on the achieved performance level in an ideal-typical way.

Improvements to push processes to a higher performance level can be achieved by innovation and continuous improvement. These are the two basic different theoretically principles that can realise improvements. Both principles need a different amount of time and both should be utilised in organisations. Small, continuous improvement steps often need more time to obtain a higher performance level than innovation leaps which lead to a generally higher level of process performance within a shorter period of time. Innovation usually means a radical improvement with crucial changes. Innovation leaps are discontinuous, often initiated by strategic decisions that are usually highly complex and interdisciplinary.

Continuous improvement means evolutionary improvement measures with slight modification steps, stabilize and incrementally increase an accomplished state of performance level even further.

\section{Definition of Process and Value Stream}

As indicated in Figure 1, processes have inputs and outputs that confine a process to the contiguous processes (upstream and downstream) and they fulfill the process purpose. The input (to be considered as an activated incident), the actual process flow and the required resources as well as the output (outcome) are basic parameters to define a process. Processes are confined on a temporarily base as well as with regards to the content. Within the process the responsibilities for the sub-processes/activities are defined as well as the required information.

The process objectives are derived top-down from the overall business objectives. They can cover general quality aspects of the business such as cost and time aspects. The commitment of process responsibilities completes the required parameters of a process (Wagner and Patzak, 2007).

A value stream includes all activities, i.e. value-adding, non-value-adding and supporting activities that are necessary to create a product (or to render a service) and to make this available to the customer. This includes the operational processes, the flow of material between the processes, all control and steering activities and also the flow of information (Figure 2). Taking a value stream view means considering the general picture of an organisation and not just individual aspects (Kuhlang et al., 2011). 


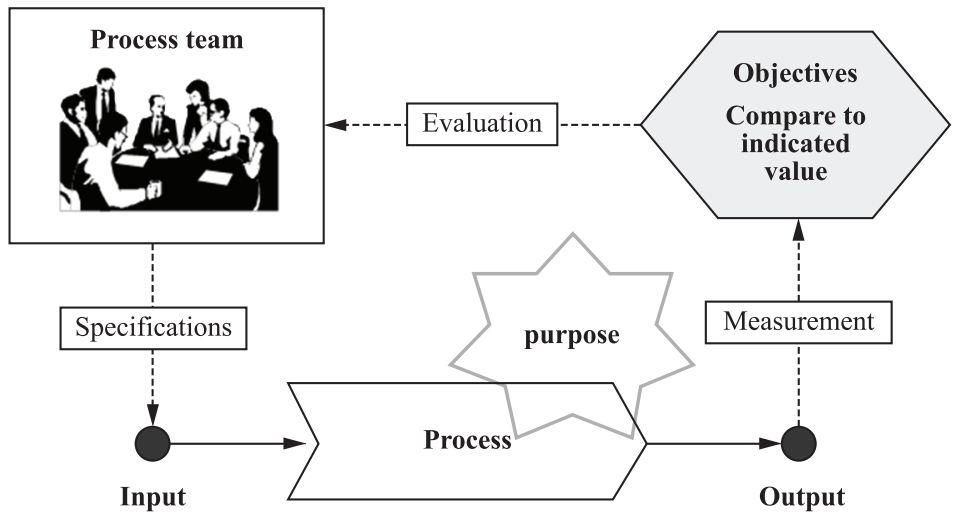

Figure 1. Process definition (Wagner and Patzak, 2007).

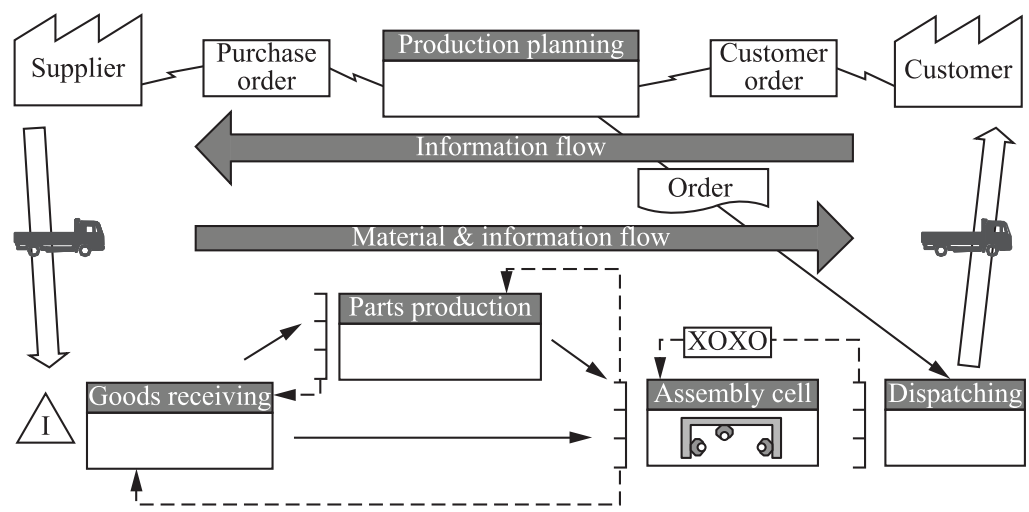

Figure 2. Picture of a value stream (the so-called value stream map).

\section{Value Stream Design and Process Management}

\section{Value Stream Mapping}

VSM was originally developed as a method within the Toyota Production System (Ohno, 1998) and is an essential element of Lean Management (Liker, 2009). It was first introduced as an independent methodology by Mike Rother and John Shook. VSM is a simple, yet very effective, method to gain a holistic overview of the status of the value streams within an organisation. Based on the analysis of the current status, flow-oriented value streams are planned and implemented for the target-status. In order to assess possible improvement potential, VSM considers, in particular, the entire operating time compared with the overall lead time. The greater the distinction between operating and lead time the higher the improvement potential (Rother and Shook, 2006; Erlach, 2007; Klevers, 2007). By defining future states, VSM uses a 4-Step approach including an "action plan" to describe necessary actions and activities (what, by whom, until when) to improve the value stream/process. 
VSM was primarily developed as a method for the improvement of production processes. Therefore, Rother and Shook have defined seven guidelines for establishing an efficient, customer-oriented value stream. Originally the method was described only for simple and discrete production process chains, but quickly the need for an extension towards mixed model value streams was discovered. Erlach and Duggan described approaches dealing with that (Erlach, 2007; Duggan, 2007). Meanwhile a further advancement of VSM has been introduced by combining it with MTM (Methods-Time Measurement) (Kuhlang et al., 2011) to increase productivity and decrease lead time. The joint application of VSM and MTM mutually aligns the design and the improvement of assembly and (production) logistic processes and takes either the workplaces, their surroundings and the supply areas as well as the overall value chain into account. The identification and exploitation of productivity potentials is realised by the joint application of VSM and MTM focusing the (work) methods, the performance and the utilisation of the processes (the dimensions of productivity) and has been specified The joint mutual benefit of the combined application arises from the increase in productivity, from the standardisation of processes, from the reduction in lead time/inventory and from the accurately determined times; it also enables and ensures the predictability and the capability to assess the target status. (Kuhlang et al., 2011).

Furthermore, the method VSM has been adapted to towards maintenance. Based on the development of an eight-step maintenance standard process which defines the standard sequence of process steps for various maintenance tasks the method Value Stream Mapping was extended to generate maintenance key figures precisely and to make areas of improvement visible (Matyas and Sihn 2011).

To apply VSM administrative processes alternative guidelines and new ways of visualisation have been defined by Wiegand (Wiegand and Nutz, 2007).

\section{Process Management}

Process Management causes a sustainable improvement of working procedures in the organisational structure: Activities are geared towards the added value. Process Management is the combination of activities which include the planning and monitoring of a process. It is also the application of knowledge, skills, tools, techniques and systems to define, visualise, measure, control, report and improve processes with the goal to meet customer requirements profitably. This improves the employees' incentive to work, because they are able to recognize the importance of their contributions in the overall context. The hub in the Process Management concept is the Process Life Cycle (see Figure 3 for a basic principle diagram).

The Process Life Cycle indicates and determines each stage of the life cycle of a process within a Process Management System. It starts with the incorporation of the process into the process map and it ends with the shutdown of the process. The Process Life Cycle defines the steps in the cycle of a process in the Process Management System in form of phases and phase transitions. Phase 1 and 2 represent the design and conception of processes. Phases 3 and 4 specify the recurring work of implementing processes. The entire Process Life Cycle can also be considered as two processes ("to design a process" and "to operate and control processes") according to the described phases. 
Another view is the combination of phase 2 and 3 focussing the "management of single processes", the combination of phase 4 and 1 focussing "management of multi processes" (Wagner and Patzak, 2007).

To define a process in the sense of disclosing and realising potentials for improvement, the 4-Step-Method (Figure 5) is used. The 4-Step-Method is a generic approach in PcM and consists of (Wagner and Käfer, 2010):

- Step I: Identification and scope (confinement);

- Step II: Analysis of actual (as-is, current-state) processes;

- Step III: Design target (to-be) processes;

- Step IV: Implementation of improvements.

Step two is keen on coming up with the so-called improvement list (Figure 4), which is used for tracking the considered actions for the purpose of improving the process. It is similar to the VSM action plan but covers broader aspects and parameters.

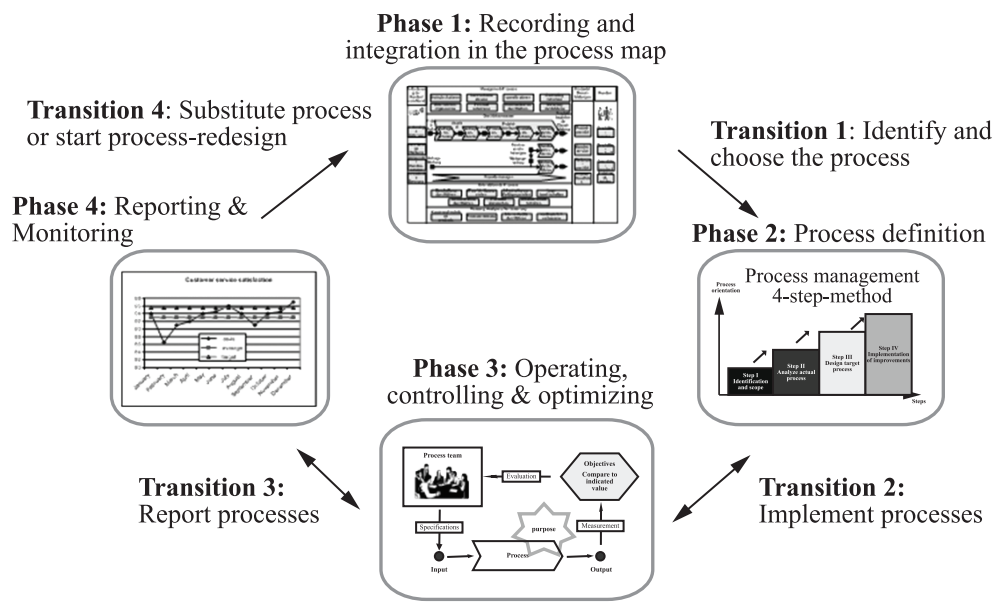

Figure 3. Process life cycle (Wagner and Patzak, 2007).

\begin{tabular}{|c|c|c|c|c|c|c|c|c|c|c|}
\hline \multicolumn{3}{|c|}{$\begin{array}{l}\text { Improvement } \\
\text { list }\end{array}$} & \multicolumn{3}{|c|}{ Process: } & \multicolumn{5}{|c|}{ Process team: } \\
\hline$\dot{z}$ & 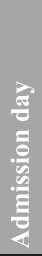 & 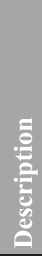 & 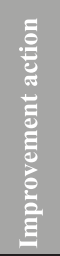 & 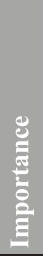 & $\frac{\bar{z}}{2}$ & $\begin{array}{l}8 \\
8 \\
0 \\
0 \\
0\end{array}$ & 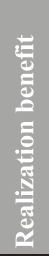 & 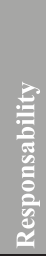 & 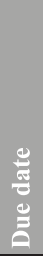 & $\frac{a}{3}$ \\
\hline \multicolumn{11}{|l|}{1} \\
\hline \multicolumn{11}{|l|}{2} \\
\hline$\ldots$ & & & & & & & & & & \\
\hline
\end{tabular}

Figure 4. Improvement list. 


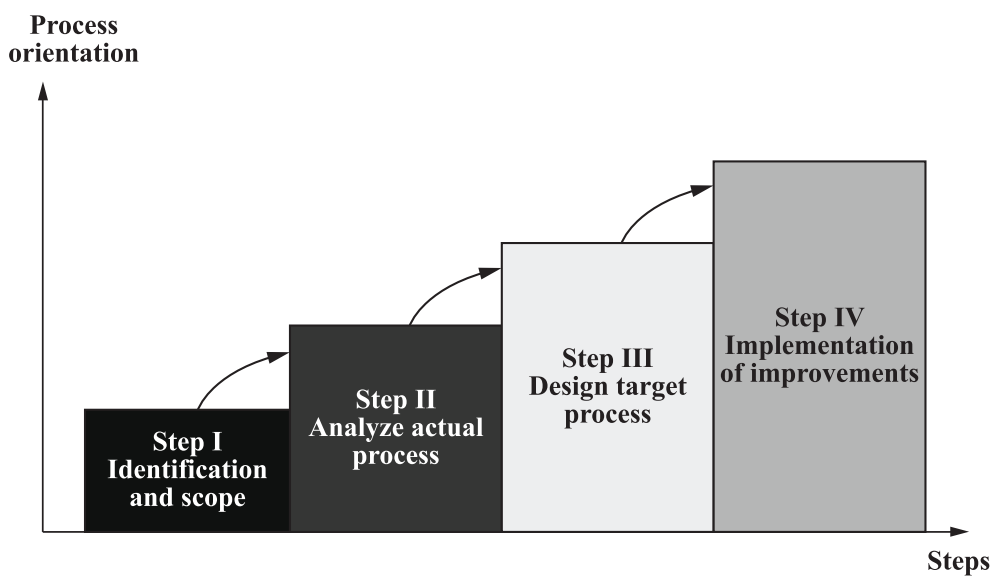

Figure 5. 4-Step approach of PcM.

The continuous improvement of the process takes place in phase 3 and 4 of the Process Life Cycle in structured Process Jour Fixe meetings (Morawetz et al., 2010).

\section{Process Life Cycle as the Fundamental Basis to Systematise VSM}

The 4-Step-Method is a procedure to design new processes, and it is also used to modify and to improve existing processes. The result of this procedure is - in most cases - a fundamentally changed, respectively improved process. The 4 steps are implemented by a sequence of - at least - four Process Team Meetings (PTM). In addition to the process owner and the members of the process team, a process coach and, depending on demand, people from other relevant areas are attending the PTMs as well. Hence it is tried to ensure gaining valuable proposals to improve processes. The so-called Process Jour Fixe (PJF) meetings are instruments for a current and continuous control of the process in phase 3 and during the transition to reporting and monitoring in phase 4. During the phase 3, adaptations and modifications of the process are continuously happening. Another task of the PJF is to record these changes, thus keeping the process documentation up to date regularly. The ongoing measurement and illustration of process performance indicators is a condition for Process Teams to influence the process in phase 3 of the Process Life Cycle. Furthermore they are also the general basis for reporting and monitoring of all the different processes. Relevant decisions about necessary improvements taken in the PJF are documented in the improvement list (Wagner and Käfer, 2010).

The 4-Step-Method in the second phase of the Process Life Cycle takes all necessary steps to define the future state of a process. This "new" process is implemented during the transition from phase 2 to phase 3 . In phase 3 , the focus is set on meeting the requirements and on identifying and realizing incremental improvement actions. This is called the "everyday life" of a process. The reporting and the monitoring of different processes and several process goals is taking place in phase 4 . Thus, the information available in phase 2 and phase 3 is broadened by relevant, respectively strategic parameters and aspects (Wagner and Käfer, 2010). All 
relevant information and performance indicators as well as actual problems in the daily life of the process are conditioned prior to a Process Management Review (PMR). Therefore they are also available for the PJF and the PTM in order to accomplish a successful decision making and to provide the basis for the deduction of necessary improvement actions.

\section{Comparing the Two 4-Step Approaches}

By comparing the two 4-Step approaches (Figure 5 and 6) within VSM and PcM, many similarities arise.

In VSM as well as in PcM, the first step is to limit and define the scope of improvement, by choosing a product family on hand or identifying and encircling a certain process on the other hand. This is in both cases an important and crucial step in order to identify and combine similar processes, but also to separate value streams or processes. Of course this step is also necessary to limit the improvement scope and to make the effort predictable up to a certain degree (Morawetz et al., 2010).

In both approaches, the current state is analyzed in step 2. PcM uses flowcharts or similar charts to visualize the current situation, VSM draws a current state map using the typical VSM-symbols. A remarkable difference occurs in the recording and analysis of data. Whereas VSM is quite strongly focused on the distinction between operating and lead time, PcM focuses on different performance indicators as well as on soft facts that cannot be measured with numbers that easily. Although not visible in Figures 5 and 6, a similarity in step 2 is the focus on customer demand and customer requirements in both approaches.

The third step is in both approaches characterized by the design of a future (target) state. Whereas VSM uses guidelines to create an efficient, customer-oriented

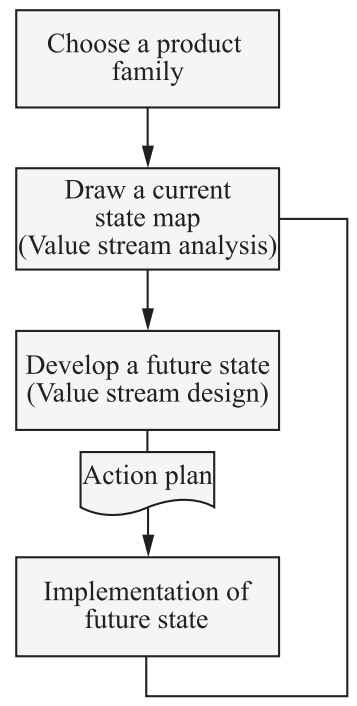

Figure 6. 4-Step approach of VSM. 
value stream to elaborate the future state, PcM uses a great variety of methods or tools (e.g. FMEA, Q7, Ishikawa-Diagram, etc.) to identify room for improvement and to elaborate the target state. Similarities are designed first by way of designing a future state that encompasses in both states an ideal state which is free from restrictions (e.g. floor space, availability of qualifies employees, etc. After that, the desired future state is derived from the ideal state, under the assumption that it can be implemented within a reasonable time frame. As visualized in Figure 7, the ideal state is subject to change. Step 4 is again quite similar in both approaches and the planned improvements are implemented.

During the execution of the 4-Step approaches (in PcM as well as in VSM) the "as is" situation is determined and an ideal state is defined as well as a target state is described at point-in-time " 1 up to n". Through the realisation of improvements, summarised in the action plan or the improvement-list, a new current "as is" state occurs at point-in-time " $n+1$ ", which can be achieved within the economical, organisational and time-delimited requirements. The objective here is set to the transference of the "as is" situation as described by point-in-time " $n$ " to the target state described by pointin-time " $n+1$ " (Figure 7). Based on this step-by-step procedure to achieve the ideal state, the necessary amount of required resources for improving the processes becomes predictable and can therefore be estimated.

These two approaches, the 4-Step-Method of PcM and the 4-Step approach of VSM, have been designed to cause a fundamental rearrangement of a process.

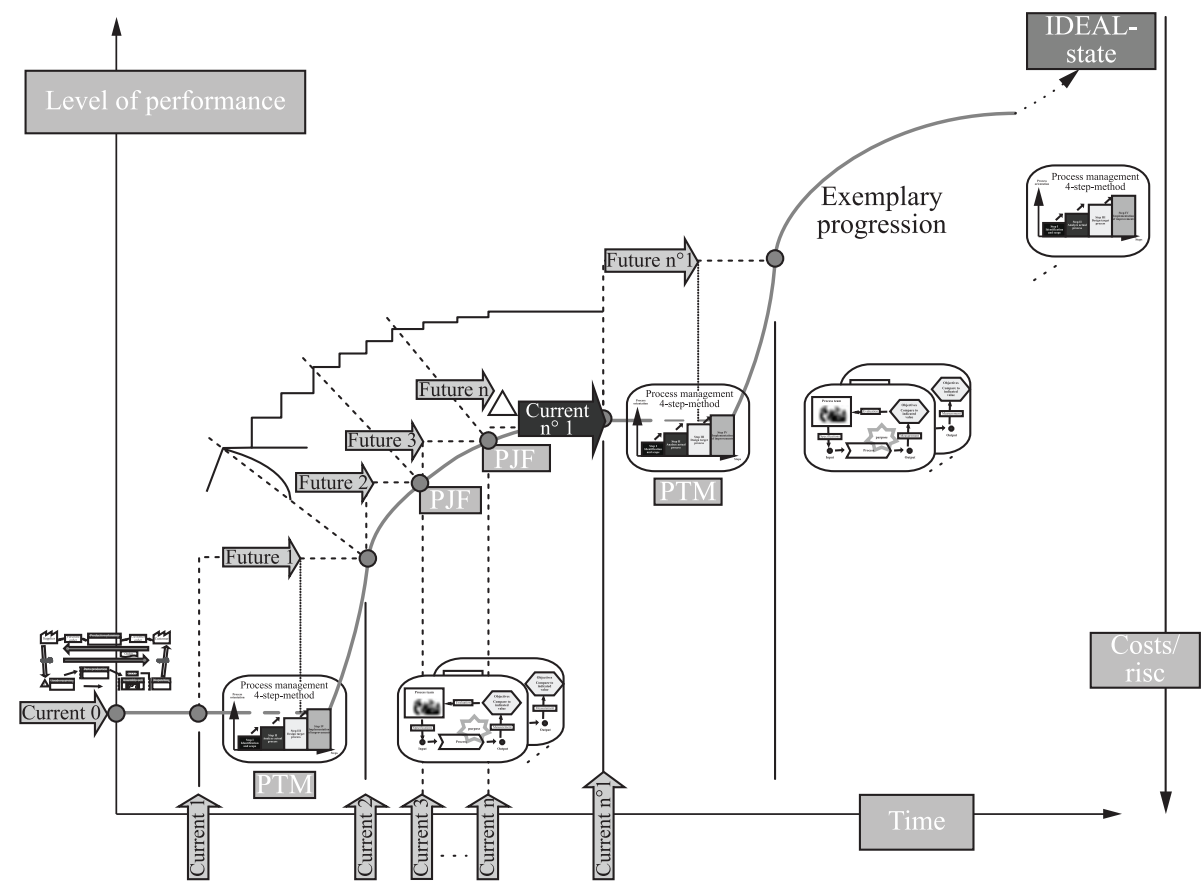

Figure 7. Innovation and continuous improvement of a values stream in the Process Life Cycle. 


\section{Systematisation of VSM}

The approach in solving the problem of systematisation respectively of standardisation of VSM is closely related to a common principle of organisation theory, the connection of continuous improvement and innovation. This interplay can also be found in the PcM-System, in phase 2 and 3 of the Process Life Cycle. These phases reflect the change between continuous improvement of a process and the big development leaps (Figure 7).

In Figure 7, the incremental improvements are depicted as a stairway. Idealtypically, the performance of a process respectively a value stream stabilises after reaching a new performance level. Nevertheless, a decline from this performance level is the reality. Phase 3 and the transition to phase 4 are acting against this natural decline. By "feeding" a small amount of energy the value stream is at least stabilised on the performance level or even improved by incremental steps. Therefore, this systematisation based on phase 3 , together with its interplay of phase 4, describes the way of using VSM for incremental improvements. The longer a value stream is improved in such a way, the smaller the improvement steps are usually getting. By no longer than in the case of missing defined target values, it is useful to break out of this behavior. Another »big step« is necessary again, and the value stream has to be transferred back to phase 2 again.

In order to systematise the VSM approach, an integration into the guidelines, approaches and meeting structures of the Process Life Cycle, and therefore into the PcM-System, may be necessary to enable a continuous improvement of value streams.

After selecting a value stream, which has to changed respectively to be improved, in phase 1, this value stream is changed fundamentally in Process Life Cycles' phase 2 "Process Definition". This innovation step can also be considered as an improvement project, is performed by using the 4-Step-Method of PcM by analyzing the current state, defining the future state and setting the figures respectively targets and actions to implement the new value stream. This new value stream is designed in at least four Process Team Meetings (PTM). Each PTM represents a milestone during a step to ensure the systematic execution of the 4-Step-Method. The phase 3 of the Process Life Cycle represents the daily life of a value stream. Constantly, small adjustments and improvements take place and the process owner is steering the value stream with the help of an improvement list and regular Process Jour Fixe (PJF) meetings (Figures 8 and 9). This set of clearly defined and structured meetings in the PcM-System ensures the continuous and innovative change of a values stream.
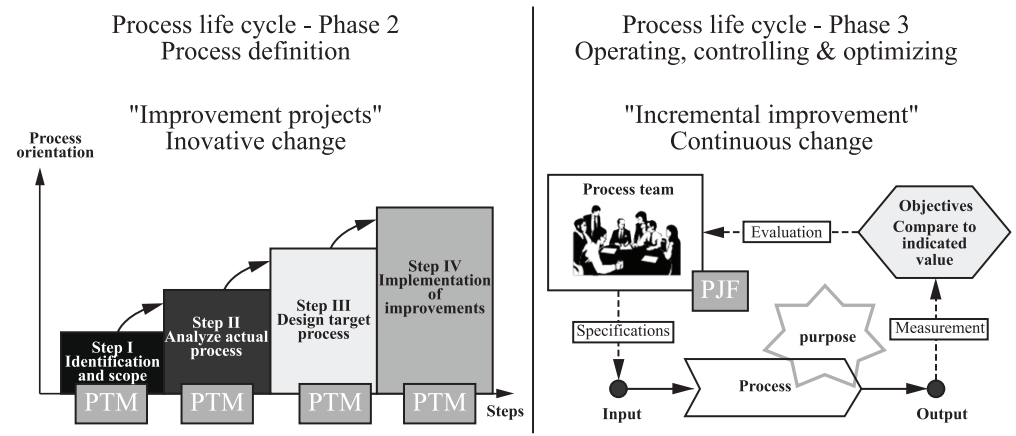

Figure 8. Set of defined and cleary structured meetings in a process management system (phases 2,3). 
Phase 4 of the Process Life Cycle has a special meaning for the development of a value stream - no matter if there are small steps or innovation leaps. The actual

\section{Performance indicators, KPIs \\ add. external information}

Phase 3: Reporting \& Monitoring

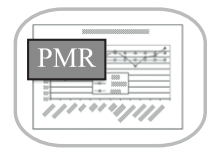

Phase 3: Operating, controlling \& optimizing

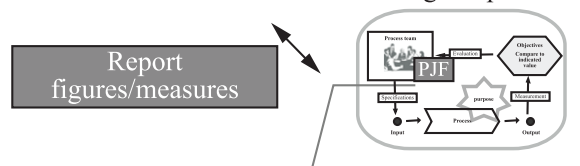

Incremental/continuous improvement meet the requirements
Define the new process (future

state), realise innovation leaps

Phase 2: Process definition

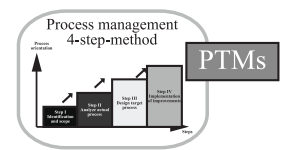

Realise "new process" implementation

Figure 9. Meeting structure in the process life cycle.

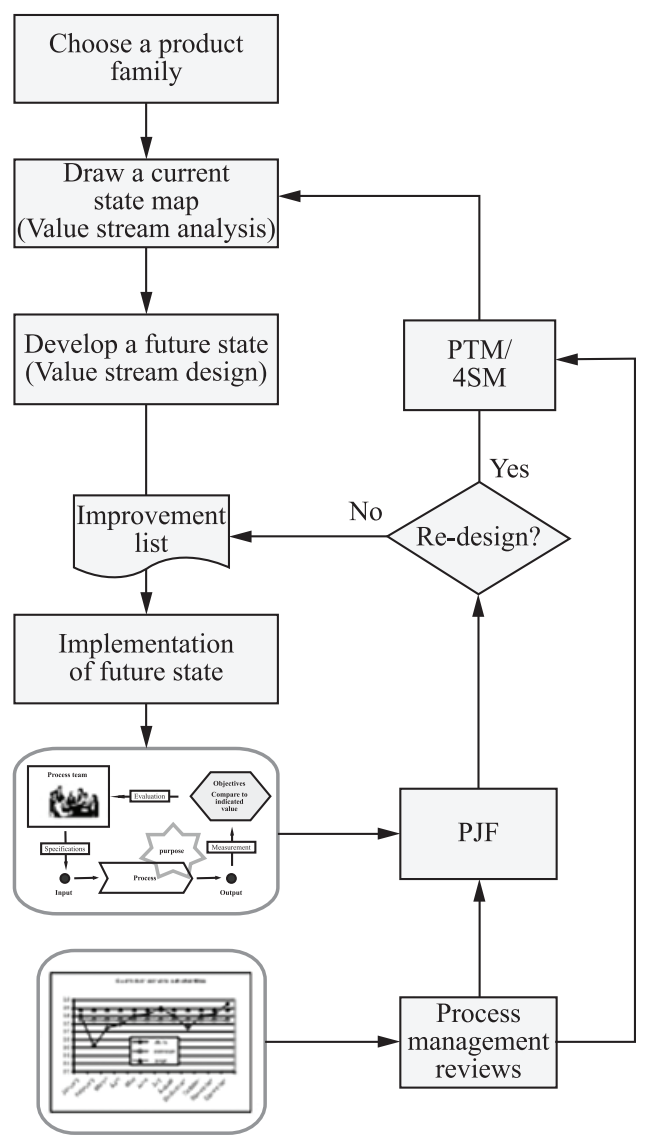

Figure 10. Procedure to systematize VSM by process management. 
performance data of the value streams and current information concerning the organization (e.g. key performance indicators) and the external influences are collected for the Process Management Reviews (PMR). Thus, makes the information available for the PTM and PJF as well (Figure 9).

Process Management Reviews help to make the performance level of value streams assessable and controllable. They provide the basis to decide if a re-design of a value stream is necessary and to set certain targets for the improvement projects. The "multi processes" monitoring activities, that are performed in phase 4 of the Process Life Cycle, are delivering the data basis for the decision whether specific value streams have to be redefined or not. The relevant data and performance indicators as well as actual problems in the daily life of the value stream have to be prepared and edited before a PMR takes place. In a PMR, the decision of sending a process »back « into phase 2, is made. Alternatively small adaptations may be sufficient, and the value stream is just going back to phase 3 and is going to be changed continuously in incremental steps. This swinging back and forth between different states of a Process Life Cycle also represents the connection between innovation and continuous improvement steps (Figure 7).

The systematisation of VSM leads to an enlargement of the 4-Step approach of VSM and is shown in Figure 10.

\section{Conclusions and Outlook}

The following outline summaries some examples of a joint application of the two approaches with relevance from a management point of view. The advantages of this combination are that incremental improvements, thus aspects of process efficiency, are merged with aspects of process effectiveness for greater improvements. VSM provides a more detailed data base of process metrics, e.g. operating times and lead times. It's classical "point in time" focus is transferred to a "period of time" application and its focus is widened from a single process to a multi process view. Clear principles and guidelines can also be used in optimising processes and an overall consideration of an organisation is accomplished.

The result of this theoretically based research is to firmly establish VSM, known for its quick and easy application, as part of the improvement routines of a well-known and scientifically accepted approach to establish PcM-Systems. The systematically embedding of VSM into a PcM-System was developed and specified. It provides a solid base for international scientific discourse and test of relevance in practical applications. This approach for the systematical and recurring application of VSM is currently being tested simultaneously in applied research projects. These results will subsequently be used to evaluate these conceptual ideas and further research steps will be defined and/or raised in the scientific community. Additional suggestions/ideas raised for further research activities are the linkage to ideas of Rothers' Kata thinking and to develop value stream reference and assessment model.

\section{References}

Abdulmalek, F. and Rajgopal, J. (2007) Analyzing the benefits of lean manufacturing and value stream mapping via simulation: A process sector case study. International Journal of Production Economics, Vol. 107, No. 1, pp. 223-236. http://dx.doi.org/10.1016/j.ijpe.2006.09.009 
Duggan, K.J. (2007) Creating mixed model value streams: practical lean techniques for building to demand. New York: Productivity Pr., pp. 173.

Erlach, K. (2007) Wertstromdesign - Der Weg zur schlanken Fabrik. Berlin Heidelberg: Springer-Verlag, pp. 114-129.

Gurumurthy, A. and Kodali, R. (2011) Design of lean manufacturing systems using value stream mapping with simulation: A case study. Journal of Manufacturing Technology Management, Vol. 22, No. 4, pp. 444-473. http://dx.doi.org/10.1108/17410381111126409

Klevers, T. (2007) Wertstrom-Mapping und Wertstrom-Design: Verschwendung vermeiden - Wertschöpfung steigern. Landsberg am Lech: mi-Fachverl., Redline, pp.30.

Kuhlang, P.; Edtmayr, T. and Sihn, W. (2011) Methodical approach to increase productivity and reduce lead time in assembly and production-logistic processes. CIRP Journal of Manufacturing Science and Technology, Vol. 4, pp.24-32. http://dx.doi.org/10.1016/j. cirpj.2011.02.001

Liker, J.K. (2009) Der Toyota-Weg: 14 Managementprinzipien des weltweit erfolgreichsten Automobilkonzerns - 6., leicht veränderte Auflage. München: FinanzBuch-Verl., pp.29-30.

Matyas, K. and Sihn, W. (2011) Standardization And Optimization Of Maintenance Processes In Lean Manufacturing Systems, in Proceedings "Innovation in Product and Production", ICPR 2011, Stuttgart

Morawetz, C.; Kuhlang, P.;Wagner, K. and Sihn, W. (2010) Value Stream Oriented Process Management, in: Proceedings Management of Technology Step to Sustainable Production - MOTSP 2010, Rovinj.

Ohno, T. (1998) Toyota Production System beyond Large-Scale Production. Portland USA: Productivity Press.

Rother, M. and Shook, J. (2006) LEARNING TO SEE (Sehen lernen - Mit Wertstromdesign die Wertschöpfung erhöhen und Verschwendung beseitigen). Aachen: Lean Management Institut, pp.29.

Vinodh, S.; Arvind, K.R. and Somanaathan, M. (2010) Application of value stream mapping in an Indian camshaft manufacturing organisation. Journal of Manufacturing Technology Management, Vol. 21, No. 7, pp. 888-900. http://dx.doi.org/10.1108/17410381011077973

Wagner, K. and Käfer, R. (2010) PQM - Leitfaden zur Umsetzung der ISO 9001, 5. komplett überarbeitet und erweiterte Auflage. Wien: Carl Hanser Verlag München, pp.57. pp.105, pp.45, pp.99.

Wagner, K. and Patzak, G. (2007) Performance Excellence - Der Praxisleitfaden zum effektiven Prozessmanagement. Wien: Carl Hanser Verlag München, pp.78-90.

Wiegand, B. and Franck P. (2006) Lean Administration 1: So werden Geschäftsprozesse transparente. Aachen: Lean Management Institut, pp.34.

Wiegand, B. and Nutz, K. (2007) Lean Administration 2: So managen Sie Geschäftsprozesse richtig. Aachen: Lean Management Institut.

\section{Biography}

Peter Kuhlang, Ass.-Prof. Dr. born 1970 in Mödling, obtained his doctor degree in Technical Sciences (Industrial Engineering) from the Technical University of Vienna. Since 2006 he is Assistant Professor at the Insitute of Management Science at the Technical University of Vienna. His area of research is Industrial Engineering and process management. He founded and is board member of the Austrian Society of Process Management and vice-president of the Austrian MTM-Association and member of the scientific board of the Organization to increase Efficiency and productivtiy.

Contact: peter.kuhlang@fraunhofer.at 
Thomas Edtmayr, Dipl.-Ing., is a researcher at Fraunhofer Austria Research $\mathrm{GmbH}$ (Division: Production Management) and also researcher at the Institute of Management Science of the Vienna University of Technology since 2009. His fields of research are Value Stream Mapping \& Optimization, Lean Production \& Management and Time Management. His practical experience gained out of industry and researchprojects constitutes a solid basis for performing in diverse trainings and lecturing at the Vienna University of Technology in the field of study Industrial Engineering.

Contact: thomas.edtmayr@fraunhofer.at

Alexander Sunk, Dipl.-Ing., is a researcher at Fraunhofer Austria Research $\mathrm{GmbH}$ (Division: Production Management) and also researcher at the Institute of Management Science of the Vienna University of Technology since 2009. His fields of research are Value Stream Mapping \& Optimization, Lean Production \& Management and Time Management and Industrial Engineering.

Contact: alexander.sunk@fraunhofer.at

Christian Morawetz, Dipl.-Ing., is research fellow at Fraunhofer Austria since 2006 and has conducted numerous industry funded applied research projects within the topics factory planning, design of internal and external supply processes and Lean Management, one of them the research project LOG4SMEs. Christian Morawetz also teaches factory planning and production management at the Vienna University of Technology.

Contact: christian.morawetz@fraunhofer.at

Wilfried Sihn, Univ.-Prof. Prof. eh. Dr.-Ing. Dr. h.c. Dipl.-Wirtsch.-Ing., is Professor at the Institute of Management Science since 2004 and head of the Institute since March 2009; Professor Sihn was Deputy Director of the Fraunhofer Institute for Manufacturing Engineering and Automation (IPA) in Stuttgart, and is Director of Fraunhofer Austria since December 2008. Professor Sihn has been active in the field of applied research and consulting services for more than 25 years now. His areas of expertise include production management, corporate organization, enterprise logistics, factory planning, order management, and business process reengineering. Professor Sihn was instrumental in developing such concepts as the Fractal Company.

Contact: wilfried.sihn@fraunhofer.at

\section{Article Info:}

Received: September, 2011

Accepted: December, 2011 